\title{
SYPHILITIC ANGINA PECTORIS
}

\author{
BY \\ EVAN JONES AND D. EVAN BEDFORD \\ From the Cardiographic Department, Middlesex Hospital \\ Received January 21, 1943
}

The first description of an actual case of syphilitic angina pectoris has been credited to Morgagni (1761). It concerned a woman, aged 42, who had anguish in the upper part of the chest, with difficulty in breathing and numbness of the left arm, provoked by exertion and promptly relieved by rest; while on a journey from Venice, she died suddenly in a paroxysm. At necropsy, the arch of the aorta was dilated, its inner surface irregular and ossified, and the valves indurated. Following Heberden's account of angina pectoris, Blackall (1814) and, later, Corrigan (1838) reported its association with disease of the aorta, which, at that time, had not been connected with syphilis. After syphilitic aortitis had been identified and separated from atheroma (Welch, 1876), its relation to angina pectoris became recognized, especially by Allbutt. His aortic theory, though no longer entertained in respect of angina pectoris in general, has never been entirely abandoned in the case of syphilitic aortitis.

Thus, Herrick (1931), in subscribing to the coronary theory, did not deny the possibility of an aortic angina which " lacks the earmarks of the typical form." Coombs (1932) remarked that certain features of syphilitic anginal pain were suggestive of a periaortic origin. Stadler (1932) found the distinction between aortalgia and mild angina pectoris difficult. This conception of an atypical or pseudo-angina of aortic origin is still current in descriptions of the symptoms of syphilitic aortitis. It was, of course, opposed by Allbutt (1915), who accused contemporary writers of withholding the diagnosis of angina pectoris at pleasure whenever the coronaries proved to be intact: "Call no man anginous until he be dead, and not even then unless he has played the game."

In investigating syphilitic anginal pain, we have paid special attention to the occurrence of any peculiar or atypical features that might be interpreted in terms of an aortalgia. In order to approach the problem of pathogenesis without bias, we have included in this inquiry all cases of paroxysmal pain the chest of anginoid type occurring in syphilitic subjects, without reference to the physical signs. Non-paroxysmal pain has been excluded; we believe that, in syphilitic cases, it can usually be attributed to pressure from a dilated aorta, and need not be confused with angina pectoris. The presence of aneurysm sometimes gave rise to difficulty in diagnosis. Osler (1906) first drew attention to the importance of angina pectoris as an early symptom of aortic aneurysm, and Mackenzie (1923) also accepted the association as common. More recently, Campbell (1936) has stated that 15 per cent of all cases of thoracic aneurysm are subject to anginal pain. We have, therefore, not excluded cases of aneurysm from consideration except when obvious pressure symptoms or signs rendered the interpretation of pain difficult.

\section{Clinical Material}

The records of 103 patients with evidence of syphilitic infection and subject to anginal pain, in the sense defined, have been analysed. They were seen by one of us in hospital and practice, mostly during the last ten years, and details of the pain were recorded personally. It is not suggested that syphilis was invariably a causative factor, for atheromatous coronary 
disease is always probable in those of appropriate age, yet aortitis cannot be excluded at any age in a syphilitic subject. In such a series of cases it should be possible to identify the essential characteristics, if any, of syphilitic anginal pain.

Evidence of Syphilis. One or more of the following criteria of syphilitic infection was present in every case.

(1) A history of primary or secondary syphilis, or of treatment for it.

(2) A positive Wassermann (W.R.) or, occasionally, Kahn reaction.

(3) Unquestionable syphilitic lesions other than cardiovascular.

(4) Aortic incompetence with a typical X-ray picture of syphilitic aortitis, that was not otherwise explicable.

A positive W.R. (or Kahn in a few cases) was recorded at some stage in 96 cases; in 9 of these, negative reactions were obtained later, after treatment. In the 7 cases without a positive W.R., two gave a history of syphilis and had typical dilatation of the aorta without hypertension, 4 had aortic incompetence with syphilitic lesions elsewhere, and 1 had aortic incompetence with a dilated aorta suggesting aortitis.

There was a history of primary or secondary syphilis in 31 cases, in 29 of which the date of infection was recorded. The interval between infection and the onset of anginal pain varied between 7 and 44 years, the average being 24 years; in 11 cases it was less than 20 years and in 18 cases 20 years or longer.

Age. The age at onset of anginal pain in these 103 cases and, for comparison, that in a series of 540 unselected cases of angina pectoris seen by one of us, is given in Table I.

TABLE I

Age Incidence of Syphilitic Angina Pectoris compared with that in a Series of Unselected Cases (Percentages)

\begin{tabular}{|c|c|c|c|c|c|c|}
\hline Age at onset of pain $\quad \ldots$ & ․ & 30-39 & $40-49$ & $50-59$ & $60-69$ & Over 70 \\
\hline Syphilitic angina -103 cases & .. & 10 & 32 & 30 & 28 & 0 \\
\hline Unselected angina -540 cases & .. & 3 & 18 & 37 & 32 & 10 \\
\hline
\end{tabular}

In syphilitic subjects angina started most frequently in the forties, but almost as often in the fifties or sixties. In Gallavardin's (1938) 252 syphilitic cases, the onset of pain was most frequent in the fifties, though fairly evenly distributed between the ages of 40 and 69 . The importance of syphilis as the cause of angina below the age of 40 has rightly been emphasized, but it must not be overlooked that syphilitic angina is actually more frequent after than before 50. Several patients in this series, with aortic incompetence, are still alive in the region of 70 years of age.

Sex. There were 80 men and 23 women, giving a sex ratio of 3.5 males to 1 female, which corresponds to the sex ratio in angina pectoris as a whole as given in recent statistics (White and Bland, 1931; Gallavardin, 1938; and Bedford, 1936).

Aortic Incompetence. This was present in 67 cases (65 per cent); occasionally it developed while the patient was under observation and subsequent to the onset of anginal pain. The incidence of aortic incompetence was 100 per cent below the age of 40,70 per cent between 40 and 50, 47 per cent between 50 and 60 , and 65 per cent over 60 years. Gallavardin found aortic incompetence in only 32 per cent of his syphilitic anginous patients. In comparison, the incidence of aortic incompetence in angina pectoris as a whole was 4.8 per cent in our 540 cases, and 5.5 per cent in Gallavardin's series.

Aortic Dilatation. The results of X-ray examination were recorded as follows:

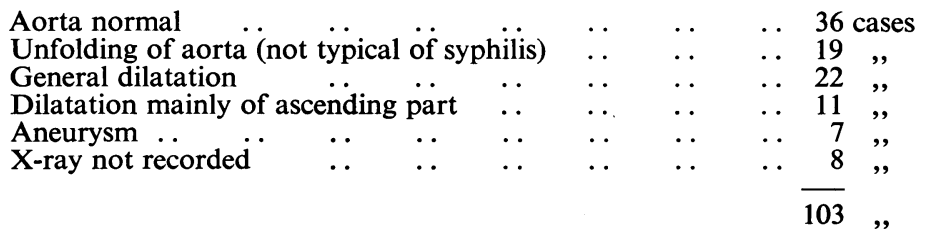


Though the aorta was widened in 59 cases (62 per cent), in only 40 was the radiological picture diagnostic of syphilitic aortitis. In Case 45-a man aged 48 in whom aortic incompetence developed terminally and subsequent to the onset of anginal pain - the aorta appeared absolutely normal in the radiograph (Fig. 1); yet necropsy disclosed generalized syphilitic

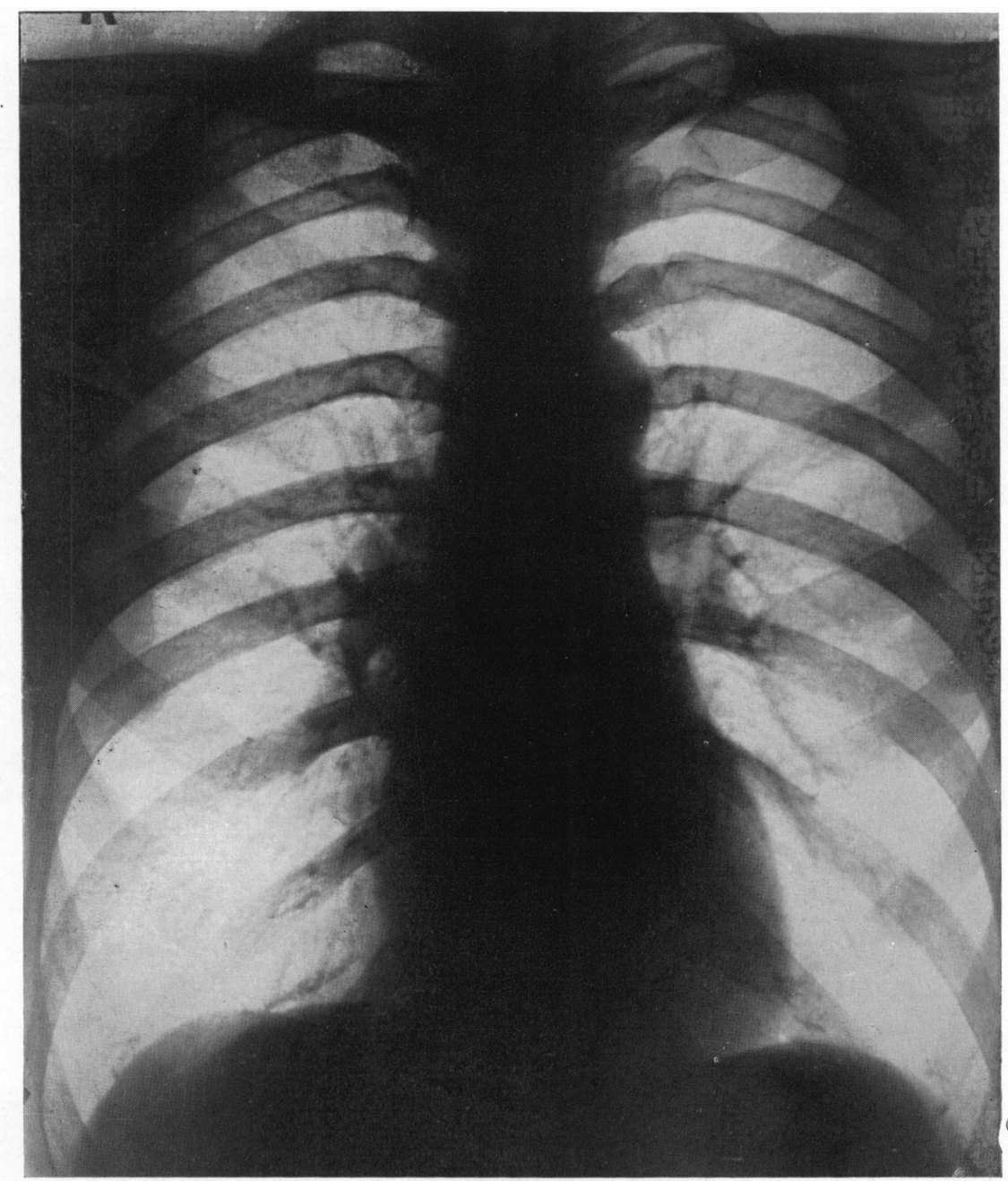

FIG. 1.-Radiograph in Case 45, showing normal appearance of heart and aorta. Necropsy showed severe syphilitic aortitis with stenosis of both coronary ostia.

aortitis without appreciable dilatation, and severe stenosis of both coronary ostia. Absence of aortic dilatation should not exclude a syphilitic ætiology in any case of angina pectoris.

Cardiac Enlargement. The heart, judged by $\mathrm{X}$-rays in all but 8 cases, was normal in size in 20 and enlarged in 83 cases; in 48 the degree of enlargement was slight. Stenosis of the coronary ostia tends to limit the process of cardiac hypertrophy in aortic incompetence, and this may explain why gross enlargement was not more common.

Blood Pressure. Normal standards of blood pressure are scarcely applicable to aortic incompetence, in which a relatively high systolic and low diastolic pressure represent the effect of cardiac hypertrophy combined with vaso-dilatation. Twenty-six patients $(25$ per cent) were regarded as having some degree of essential hypertension because of a systolic pressure of at least $200 \mathrm{~mm}$. or a diastolic of at least $100 \mathrm{~mm}$., or both. Thirteen patients had systolic pressure of $170-200 \mathrm{~mm}$. with normal or low diastolic pressures, and this was regarded as the effect of aortic incompetence. In the remainder, pressures were below these 
levels. Thus, hypertension is somewhat less frequent in syphilitic than in non-syphilitic angina pectoris.

Electrocardiogram. Records were obtained in 94 cases. They were normal in 37 and abnormal-or became abnormal-in 57 cases. Significant $\mathrm{T}$ wave abnormalities occurred in 47 , bundle branch block in 5, significant notching of QRS in 18, and 4 showed A-V block of some degree. Transient R-T changes were recorded in the course of severe anginal episodes in 5 cases. Of 12 cases with a terminal status anginosus or stenosis of the coronary ostia at necropsy, the cardiogram was abnormal in 10 ; bundle branch block occurred in 3, T I inversion in 2, T II and T III inversion in 4, and T inversion in all leads in 1 case. In Case 45, dying in a status anginosus, with severe stenosis of both coronary ostia at necropsy, the curve was normal within a few days of death. In only 2 of these cases was significant R-T deviation recorded; once it was of opposite and once of similar direction to the $T$ waves. The reciprocal $R-T$ and $T$ changes characteristic of myocardial infarction are not usually observed in ostial obstruction. This was also the experience of Muijden and Scherf (1934), of Levy (1936), and of Zimmermann-Meinzigen (1936).

Site of the Pain. It is often stated that the pain of syphilitic aortitis is unusual or atypical in its distribution in comparison with that of angina pectoris proper (Reid, 1930; Coombs, 1930). In the majority of our syphilitic cases the pain was either central or extended horizontally and more or less symetrically across the chest; its level was approximately midsternal in 55 cases and in the remainder at the upper or lower thirds of the sternum with almost equal frequency. Pain often spread to the neck or throat ( 25 cases), to the back (18 cases), and to the shoulders, axillæ, and arms. It affected both arms in 38 cases, the left only in 19, and the right only in 2; this applies to the more severe attacks and not to milder ones in which pain was more confined.

In 7 cases pain started in the left chest and spread to the sternum, in 2 it started posteriorly in the interscapular region, and in 4 in the arms. In only 7 cases could the pain be described as eccentric; in 4 of these it was situated in the left chest and in 3 in the right chest. Such an eccentric distribution is found in a similar proportion of cases of non-syphilitic angina pectoris.

The traditional term substernal describes appropriately enough the brief oppression or tightness in the chest on effort which is quickly relieved by halting, but it is an inadequate description of the distribution of severe or prolonged anginal pain, for example in coronary thrombosis or in the nocturnal attacks of syphilitic aortitis. In the present cases, pain was often widespread and involved the spine, neck, or shoulders, but to describe it as atypical or unusual would be unwarranted.

\section{Clinical Varieties of Anginal Pain}

(1) Angina of Effort. There were 76 patients who were subject to fairly typical anginal pain on exertion, relieved by halting. This was sometimes more severe and more lasting than the usual effort pain. In 13, pain provoked by effort persisted in some degree for 5 to 30 minutes, but it was almost always amenable to nitrites when prescribed. Pain that subsides slowly has been described as characteristic of aortitis (Barrie, 1912; Laubry et al., 1925; and Reid, 1930). Yet Heberden, in describing angina pectoris, wrote: "After it has continued a year or more, it will not cease as instantaneously upon standing still." The following example may be cited.

Case 75. Male, aged 56, first seen August 1934. Syphilis denied. For 2 years subject to pain across chest at mid-sternal level, extending into both arms, provoked by effort and persisting sometimes for as long as an hour. Recently, onset of nocturnal attacks of pain lasting up to an hour, with palpitation and dyspnœea, relieved by nitrites.

Examination. Pulse, regular and collapsing. Arteries, thickened. B.P., 200/70. Aortic diastolic murmur; gallop rhythm at apex. X-ray: slight enlargement of heart and widening of aorta; no signs of congestive failure. EC., normal. W.R., positive. 
Course. After rest and mercurial treatment, improved but liable to effort pain. In October 1936, pain more frequent with severe nocturnal attacks, and dyspnœic paroxysms. In August 1937, in hospital with spontaneous anginal attacks accompanied by paroxysmal dyspnœa. EC., bundlebranch block. Died, with increasing pulmonary œdema.

Necropsy. Great hypertrophy of left ventricle and dilatation of right. Gross syphilitic aortitis and deformity of aortic cusps. Right coronary orifice occluded and left orifice stenosed. Coronary trunks normal. Bilateral hydrothorax and pulmonary œdema.

(2) Angina apart from Effort. Paroxysmal pain unrelated to effort, either nocturnal or diurnal, occurred in 64 cases, 37 of which also had effort pain. Of the 27 patients without effort pain, 8 were considered to be cases of coronary thrombosis probably associated with atheroma. It is evident that spontaneous and especially nocturnal anginal pain is far commoner in syphilitic than in non-syphilitic anginous subjects. As this kind of pain has been so often described as characteristic of aortitis, as opposed to cardiac ischæmia, we shall consider it in detail under the following headings.

(a) Nocturnal angina.

(b) Spontaneous diurnal angina.

(c) Angina associated with paroxysmal dyspnœa (paradyspnœic angina).

(d) Syphilitic status anginosus.

(e) Cardiac infarction syndrome.

(a) Nocturnal Angina Pectoris. Forty-four patients (43 per cent) were subject to nocturnal anginal attacks. If the pain occurred in the early hours of sleep, it was apt to recur once or more before morning; but in some patients it occurred only in the later hours. Occasionally it was described as continuing on and off all night. Pain tended to be severe and persistent, lasting 5 to 30 minutes or even longer unless relieved by nitrites. Patients tend, however, to over-estimate its duration. Some experienced a remarkable predominance of nocturnal attacks which occurred from the start and continued over periods of years. As Gallavardin puts it, these martyrs of the night may be little troubled in the daytime, especially if they avoid effort.

Nitrites almost invariably gave relief and once prescribed were apt to be consumed in extraordinary quantities. An opiate or other sedative at bedtime was often effective in preventing nocturnal pain, and a late or heavy evening meal always aggravated it. Patients with nocturnal angina seem particularly sensitive to a full stomach. The influence of posture is evident in many patients. Some of them experienced pain when lying down, even if awake and in the daytime, whereas sitting upright, standing, or walking about usually afforded some relief. A return to the horizontal posture favoured a recurrence of pain and recourse to sleeping in a chair was occasionally necessary. These repetitive nocturnal paroxysms were described by the earliest writers on angina, for example, Heberden (1802), Parry (1799) and Black (1819). Black's four patients, among the earliest in which coronary disease was demonstrated at necropsy, all had frequent nocturnal attacks and one patient used to sit up on a chair to "baffle the paroxysms."

Palpitation during the attack was a common complaint and tachycardia was frequently confirmed by observation. Blood pressure readings during nocturnal pain were scanty, but a rise of pressure was recorded in several cases. We are satisfied that paroxysmal dyspnœa is not an essential or usual accompaniment of nocturnal pain, as French writers-excepting Gallavardin-have assumed. Cases in which this combination did occur are separately considered.

In a series of 200 unselected cases of angina pectoris, 23 per cent were subject to nocturnal pain compared with 43 per cent in the syphilitic series. The frequency of nocturnal attacks in syphilis has been insufficiently recognized though it has not altogether escaped notice, for example, by Willius (1936) and Oille (1937); it is easily confirmed by reference to published case records such as those of Mackenzie (1923), Osler (1897) and Gallavardin (1925). Aortic 
incompetence is the rule and occurred in 77 per cent of our cases with nocturnal pain. The following example is briefly cited.

Case 79. Man, aged 64, first seen September 1926, while under treatment for tertiary syphilitic lesions of mouth. Started attacks of severe mid-sternal pain radiating to spine, unrelated to effort and usually nocturnal.

Examination. Slight enlargement of heart and dilatation of ascending aorta (X-ray). Accentuated aortic second sound; no aortic incompetence. B.P., 150/100. EC., left axis deviation; P-R prolonged, QRS and T normal.

Course. Following rest and anti-syphilitic treatment free from pain for over 2 years, when it recurred. Attacks nocturnal or provoked by lying flat and relieved by sitting up. Became shortwinded, signs of aortic incompetence were noticed, and congestive failure soon followed. Improved with treatment for heart failure. In 1934 in hospital with further congestive failure and hydrothorax. B.P. 210/80. Died at home in January 1937, 11 years after the onset of anginal pain.

(b) Spontaneous Diurnal Anginal Pain. Pain apart from effort during the daytime occurred in 22 cases, half of which were also subject to effort pain and most to nocturnal pain. Such factors as emotion, meals, cold, etc., were often operative. The effect of posture was also mentioned by some patients in whom reclining, stooping, or bending might precipitate pain. The attacks tended to be severe and prolonged and were sometimes accompanied by sweating and palpitation, but were amenable to nitrites when available. Perhaps the most remarkable feature in these syphilitic patients was the period of time-even years-over which severe and prolonged anginal pain occurred without objective signs of deterioration of the heart or failure appearing. Sometimes there were intervals of relative freedom of even remissions.

(c) Paradyspnaic Anginal Pain. In the past, cardiac asthma was often confused with angina pectoris and even to-day this confusion persists in descriptions of so-called angina of decubitus. Acute pulmonary œdema may start with a feeling of oppression in the chest due to pulmonary engorgement, and this has undoubtedly passed as angina of decubitus. Gallavardin (1933) refers to this sense of oppression as paradyspnœic angor, but does not confuse it with angina pectoris. Admitting occasional difficulty in differentiating between the two, there is no doubt that genuine anginal pain, radiating to both arms, is sometimes combined with paroxysmal dyspnœa, as recognized by Osler (1897), Merklen (1908), and later by most writers on cardiac asthma (Pratt, 1926; Bedford, 1939).

Thirteen patients suffered from these combined paroxysms which were often but not always nocturnal. Pain occurred first and persisted until dyspnœa supervened, followed by some degree of pulmonary œdema. Nitrites were often given at the start of the attack and seemed to afford a measure of relief, but morphia was usually required. Like all forms of cardiac asthma, the anginal type complicates the terminal stages of heart disease, though the paroxysms may cease for a time with rest and treatment, or if congestive failure becomes established. The following example may be cited:

Case 100. Woman, aged 44, first seen in December 1938. No rheumatic or syphilitic history. Good health until 6 months earlier, when she became breathless on exertion.

Examination. Pulse, regular. B.P., 140/75. Arteries normal. Heart not appreciably enlarged; ascending aorta prominent (X-ray). Aortic diastolic murmur. EC., normal rhythm; T I negative. W.R. positive.

Course. Temporary improvement with rest in bed and oral anti-syphilitic medication. In February 1939, paroxysmal dyspnœa and admitted to hospital. There showed a series of severe anginal attacks, each succeeded by paroxysms of dyspnoea with blood-stained expectoration and transient signs of pulmonary odema. Pain, sternal, spreading down both arms and of great intensity; morphine gave relief in 5 to 20 minutes. Frequent attacks of this kind for several weeks, the blood pressure falling progressively; died of left heart failure in March 1939.

Necropsy. Syphilitic aortitis, aortic incompetence, and almost complete occlusion of both coronary ostia. No macroscopic infarction of myocardium.

(d) Syphilitic Status Anginosus. The symptoms produced by stenosis or occlusion of the coronary ostia complicating aortitis, previously described as an " ingravescent anginal state" (Parkinson and Bedford, 1928), can usually be distinguished from the clinical syndrome of 
coronary thrombosis or occlusion with massive focal cardiac infarction. Nine patients in this series presented the symptoms of ostial obstruction, and in 7 of them necropsies were obtained and confirmed the diagnosis.

Typically, a patient subject to effort pain begins to have spontaneous attacks which increase in frequency and severity, occurring in the daytime and at night. Repetitive seizures culminate in a status anginosus with falling blood pressure and often with dyspnca and pulmonary œdema. It has frequently been stated that the duration of life from the first appearance of pain in these cases is a matter of months, but in only 2 of our fatal cases was it less than a year, the average being two years and the longest five years. Aortic incompetence is almost invariably present; in all our necropsies the cusps were deformed, though in one case clinical incompetence was absent, and in another it did not appear until shortly before death, and subsequent to the onset of repetitive anginal attacks.

One patient survived a status anginosus of the sort described. This was a woman, aged 34 , with syphilitic aortic incompetence. Five months after the onset of angina of effort, she began to have spontaneous attacks of pain during the daytime and at night. While resting in hospital about 100 severe attacks were recorded and repeated doses of morphine were required. Gradually she became almost moribund, the blood pressure falling to $85 / 60 \mathrm{~mm}$.; but after 6 weeks she began to improve slowly and later anti-syphilitic treatment was started. She left hospital and was still alive 6 years later, though subject to frequent anginal pain.

The following case is illustrative of the 8 who died.

Case 16. A man, aged 44, had complained for two years of a crushing pain in the chest on exertion, relieved by rest. Pain started at mid-sternum and spread to throat, down both arms, and to right scapula. Following an attack lasting half an hour, pain became more frequent and severe, occurring at night and apart from effort. Brought to hospital in a severe anginal seizure requiring morphia and lasting 7 hours.

Examination. Pulse, regular and collapsing. B.P., 140/50. Arteries, thickened. Aortic to-and-fro murmurs. No signs of congestive failure. W.R., positive. X-ray: gross enlargement of heart to left; aorta normal. EC.: inversion of T in leads I, II, and IV; later T inverted in all limb leads but upright in lead IV.

Course. Recurrent attacks of pain were followed by hæmoptysis and falling blood pressure. Some improvement, then status anginosus with sweating, dyspnœe, progressive collapse, and signs of pulmonary and systemic congestion. He died two years after he was first seen.

Necropsy. Heart: $25 \mathrm{oz}$; general enlargement; ante-mortem clot in right auricular appendix. Syphilitic aortitis without much dilatation of aortic lumen; aortic cusps deformed and incompetent. Right coronary orifice completely occluded and left orifice severely stenosed. Coronary trunks patent throughout with only slight fatty atheroma. Some stenosis of orifices of innominate and left common carotid arteries. No naked-eye cardiac infarction. Infarcts of left lung.

The symptoms of syphilitic stenosis of the coronary ostia might be likened to those of coronary thrombosis in slow motion. The prodromal anginal attacks apart from effort extend over weeks or months, and the terminal state of collapse with failure develops gradually. When such a train of events is associated with syphilitic aortic incompetence, stenosis of the coronary ostia may safely be diagnosed. As already mentioned, cardiograms, though likely to be abnormal, rarely show the classical serial changes of cardiac infarction, and normal records may be obtained within a short time of death.

It is not suggested that ostial stenosis always causes anginal symptoms; there may be paroxysmal dyspnœa and failure without pain, or sudden unexpected death. Anginal pain occurred in 13 of Pincoffs and Love's (1934) 15 necropsy cases of ostial stenosis, in 23 of Cormia's (1935) 35 cases, and in 8 of Lamb and Turner's (1932) 19 cases.

(e) Cardiac Infarction. Ten patients in this series exhibited isolated severe anginal episodes corresponding to the classical syndrome of acute coronary occlusion, and accompanied by cardiographic signs of cardiac infarction. Only 3 had aortic incompetence. Though no post-mortem evidence is available in this group, it is probable that syphilis was no more than coincident with coronary atheroma and thrombosis. Published necropsy statistics show that such a coincidence is not rare (Lamb and Turner, 1932). Statistics of coronary thrombosis 
give the incidence of syphilis as 5 to 10 per cent, but this probably includes cases of coronary' ostial occlusion.

\section{Anatomical Pathology of Syphilitic Angina}

In the 12 cases that came to necropsy, 11 of the specimens were examined by one or both of us; the remaining necropsy was performed elsewhere and the state of the coronary ostia was not specifically recorded. The essential clinical and pathological data are given in Table II.

TABLE II

Clinical and Pathological Findings in 12 Cases of Syphilitic Angina Pectoris

\begin{tabular}{|c|c|c|c|c|c|}
\hline \multirow{2}{*}{ Case } & \multirow{2}{*}{$\begin{array}{l}\text { Age (at } \\
\text { death) and } \\
\text { Sex }\end{array}$} & \multirow{2}{*}{$\begin{array}{l}\text { Type of pain and clinical } \\
\text { features }\end{array}$} & \multicolumn{3}{|c|}{ Post-mortem findings } \\
\hline & & & $\begin{array}{l}\text { Aortic } \\
\text { incom. }\end{array}$ & Coronary ostia & Aorta \\
\hline 5 & $\mathrm{M} / 41$ & $\begin{array}{l}\text { A.P. effort (5 months). Sudden } \\
\text { death }\end{array}$ & $\stackrel{+}{+}$ relative & $\begin{array}{l}\text { R. severe stenosis } \\
\text { L. occluded }\end{array}$ & $\begin{array}{l}\text { Aortitis, diffuse dila- } \\
\text { tation. Stenosis, L. } \\
\text { carotid }\end{array}$ \\
\hline 12 & $F / 43$ & A.P. effort (18 months) & $\begin{array}{c}+ \\
\text { not } \\
\text { clinical }\end{array}$ & $\begin{array}{l}\text { R. occluded } \\
\text { L. severe stenosis }\end{array}$ & $\begin{array}{l}\text { Aortitis, moderate di- } \\
\text { latation }\end{array}$ \\
\hline 16 & $\mathrm{M} / 44$ & $\begin{array}{l}\text { A.P. effort ( } 2 \text { years). Nocturnal } \\
\text { and status anginosus }\end{array}$ & + & $\begin{array}{l}\text { R. occluded } \\
\text { L. severe stenosis }\end{array}$ & $\begin{array}{l}\text { Aortitis, stenosis of } \\
\text { innominate and L. } \\
\text { carotid }\end{array}$ \\
\hline 21 & $\mathrm{M} / 45$ & $\begin{array}{l}\text { A.P. effort ( } 2 \text { years). Nocturnal, } \\
\text { paradyspnœic and status an- } \\
\text { ginosus }\end{array}$ & + & $\begin{array}{l}\text { R. } \\
\text { L. }\} \text { almost occluded }\end{array}$ & $\begin{array}{l}\text { Aortitis, diffuse dila- } \\
\text { tation. Stenosis in- } \\
\text { nominate and L. } \\
\text { subclavian }\end{array}$ \\
\hline 30 & $M / 64$ & $\begin{array}{l}\text { A.P. effort ( } 3 \text { years). Congestive } \\
\text { failure. Sudden death }\end{array}$ & + & $\begin{array}{l}\text { R. } \\
\text { L. j patent }\end{array}$ & $\begin{array}{l}\text { Aortitis and athero- } \\
\text { ma; diffuse dilata- } \\
\text { tion }\end{array}$ \\
\hline 34 & $\mathrm{M} / 60$ & $\begin{array}{l}\text { A.P. effort (5 months). B.P. } \\
260 / 130\end{array}$ & + & Not recorded & Aortitis and dilatation \\
\hline 36 & $\mathrm{M} / 54$ & $\begin{array}{l}\text { A.P. effort ( } 3 \text { years). Nocturnal } \\
\text { and status anginosus }\end{array}$ & + & 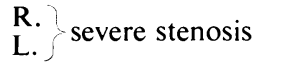 & Aortitis \\
\hline 45 & $\mathrm{M} / 48$ & A.P. effort (7 months) & slight & $\begin{array}{l}\text { R. slight stenosis } \\
\text { L. severe stenosis }\end{array}$ & $\begin{array}{l}\text { Aortitis } \\
\text { No dilatation }\end{array}$ \\
\hline 62 & $\mathrm{~F} / 44$ & $\begin{array}{l}\text { A.P. effort ( } 8 \text { years). Nocturnal } \\
\text { (3 years). Sudden death }\end{array}$ & + & $\begin{array}{l}\text { R. } \\
\text { L. }\} \text { severe stenosis }\end{array}$ & Aortitis \\
\hline 75 & $\mathrm{M} / 56$ & $\begin{array}{l}\text { A.P. effort ( } 5 \text { years). Paradys- } \\
\text { pnœic. Status anginosus }\end{array}$ & $\stackrel{+}{+}$ & $\begin{array}{l}\text { R. severe stenosis } \\
\text { L. slight stenosis }\end{array}$ & $\begin{array}{l}\text { Aortitis } \\
\text { Dilatation }\end{array}$ \\
\hline 95 & $\mathrm{M} / 38$ & $\begin{array}{l}\text { Paradyspnœic A.P. (5 months). } \\
\text { Congestive failure }\end{array}$ & $\stackrel{+}{+}$ & $\begin{array}{l}\text { R. stenosed } \\
\text { L. patent }\end{array}$ & $\begin{array}{l}\text { Aortitis } \\
\text { No dilatation }\end{array}$ \\
\hline 100 & $\mathrm{~F} / 44$ & $\begin{array}{l}\text { Paradyspnœic A.P. (1 month). } \\
\text { Status anginosus }\end{array}$ & + & $\begin{array}{l}\text { R. } \\
\text { L. }\} \text { almost occluded }\end{array}$ & $\begin{array}{l}\text { Aortitis } \\
\text { Slight dilatation }\end{array}$ \\
\hline
\end{tabular}

Of the 12, 10 had angina of effort, 5 nocturnal angina, 4 paradyspnœic angina, and 7 a terminal status anginosus. All but one had clinical aortic incompetence. Necropsy showed syphilitic aortitis in every case, some degree of aortic dilatation without saccular aneurysm in 10, and deformity of the aortic cusps in all. Stenosis or occlusion of one or both coronary orifices was present in 10 , absent in 1 , and probably absent in the remaining case, though not specifically so recorded. Both orifices were involved in 9 , and the right orifice alone in 1 case. 
The right orifice was the more obstructed in 4 , the left in 2 , and they were equally involved in 3 cases. Thus, on the whole, the right orifice was slightly more involved than the left, as previous investigators have reported.

In many published post-mortem statistics relating to syphilitic aortitis, compiled by those who did not themselves examine the patient during life, painful symptoms are imprecisely or inadequately described. Analysis of such statistics has a limited value in relation to the pathogenesis of syphilitic anginal pain.

Gallavardin (1925) gives full clinical and pathological findings in 8 cases of syphilitic angina personally observed. On these, 7 had stenosis of or occlusion of one or both coronary ostia, 4 had aortic incompetence, and 3 had coronary atheroma. The single case with neither aortic incompetence nor ostial stenosis had atheromatous coronary obstruction, and the pathological evidence of syphilis was regarded as doubtful. Clinically these patients had often exhibited nocturnal and paradyspnœic anginal pain; a terminal status anginosus occurred in 2 of them. Lamb and Turner (1932) give necropsy findings in 18 cases of syphilitic angina. Eleven of them had aortic incompetence and all showed coronary pathology; 5 had ostial stenosis alone or combined with coronary atheroma, 9 had coronary atheroma (4 with thrombosis), and 1 occlusion of the right coronary orifice by aneurysmal pressure. ZimmermannMeinzigen (1936), in 20 cases of syphilitic angina examined at necropsy, found coronary ostial stenosis in 15 and coronary atheroma with thrombosis in 2; most of them also had aortic incompetence.

Analysis of the post-mortem records of 58 cases of syphilitic aortitis from the records of the Bland-Sutton Institute of Pathology showed 14 cases of coronary ostial stenosis; 10 had angina pectoris, 2 died of failure without pain, and 2 suddenly, no clinical history being available. 12 of them had aortic incompetence. Anginal pain occurred in 16 of these 58 cases (28 per cent); 8 had aortic incompetence combined with stenosis of the coronary ostia, 3 aortic incompetence alone, 2 ostial stenosis alone, and 3 aortic incompetence combined with coronary atheroma or occlusion.

Massive localized cardiac infarction does not result from ostial occlusion, though sometimes patchy necrosis may be visible to the naked eye. All sections of the myocardium that we have examined have shown widespread microscopic areas of ischæmic necrosis or fibrosis of the myocardium. These myocardial changes resulting from ostial obstruction have been described in detail by Love and Warner (1934).

It has often been stated that anginal pain may occur in cases of uncomplicated aortitis, but the pathological evidence of this is no more convincing to-day than in Allbutt's time. We ourselves have not encountered any case of uncomplicated aortitis with intact coronary vessels at necropsy in which anginal pain occurred during life. Wilson (1937) from a study of uncomplicated aortitis concluded that it was a symptomless condition. Levy (1936) stated that cardiac pain is not to be regarded as a clinical manifestation of uncomplicated aortitis.

The essential pathological findings in syphilitic angina pectoris are, therefore, aortic incompetence or obstruction of the coronary ostia, or both together, combined with aortitis. Coronary atheroma may be associated with syphilitic aortitis, though it is rarely severe when there is ostial obstruction.

\section{The Functional Pathology of Syphilitic Angina Pectoris}

Allbutt's views on the aortic origin of anginal pain are too distorted by his uncompromizing opposition to the coronary theory to bear recapitulation to-day. But the hypothesis of an aortalgia simulating yet distinct from cardiac pain, a sort of syphilitic pseudo-angina, deserves serious consideration. Reid (1930) states that, in comparison with angina pectoris, the pain of syphilitic aortitis is not particularly under the sternum, is unrelated to effort, is of longer duration, and is apt to be nocturnal, but he admits that the distinction involves a 
large degree of the personal equation. Others have described aortic pain as frequently accompanied by paroxysmal dyspnœa (Barie, 1912; and Longcope, 1913); as provoked by the dorsal decubitus (Laubry et al., 1925); as unrelieved by rest (Stadler, 1932); and as unusual in distribution and occurring at rest (Coombs, 1930).

With regard to the distribution of pain, it was often widespread in our syphilitic cases, but not different from that of severe anginal pain in general. In other respects, however, the descriptions of aortalgia that have been cited may be accepted as applicable to our syphilitic patients. The pain was frequently nocturnal and unrelated to effort, tended to be prolonged, and when provoked by effort did not always subside quickly with rest. It was sometimes combined with paroxysmal dyspnœa. None of these features can be accepted as peculiar to syphilitic cases and it must not be overlooked that most of our patients were also subject to typical effort pain. Nocturnal attacks occur in about one fifth of all cases of angina of effort (Gallavardin, 1925); they were described as part of the disease by Heberden and have been accepted as such by subsequent writers. With regard to duration, spontaneous and nocturnal anginal attacks certainly last longer than the usual brief oppression due to effort. Prolonged pain occurs in coronary thrombosis and also in the course of progressive atheromatous coronary obstruction. Blumgart and others (1940) have used the term coronary failure to denote these severe and long anginal paroxysms which, occurring especially in cases of multiple coronary obstruction, they attribute to a prolonged but reversible cardiac ischæmia. Long duration is not, by itself, a valid reason for assuming that pain is aortic. Anginal attacks accompanied by paroxysmal dyspnœa or pulmonary œdema are certainly not confined to syphilitic heart disease. Those who regarded cardiac asthma as arising reflexly from the aorta, naturally explained associated pain in the same way. But present knowledge of the pathogenesis of cardiac asthma suggests a cardiac basis for paradyspnœic pain. As far as its clinical characteristics are concerned, therefore, there is nothing to exclude the paroxysmal pain of syphilitic aortitis being regarded as anginal and as explicable in terms of cardiac ischæmia.

Lewis (1929-31) has identified a special anginal syndrome in aortic incompetence and has cited examples of it previously described by Lauder Brunton and others. Its main features comprise tachycardia, transient elevation of blood pressure, relatively long duration, and prompt relief by nitrites. The attacks may be induced by effort, or may occur spontaneously after meals, at rest, or at night. One of Lewis's cases was syphilitic, but several of those cited were rheumatic. In our experience and in that of others (White and Mudd, 1927) spontaneous and nocturnal anginal attacks are common in cases of rheumatic aortic incompetence, where aortitis and coronary obstruction can often be excluded. It is usually held that the low diastolic pressure of aortic reflux predisposes to cardiac ischæmia by virtue of its adverse effect on coronary flow. Lewis postulated a general vaso-constriction involving the coronary vessels, and concluded that nitrites relieved the pain mainly by coronary vaso-dilatation. In many syphilitic cases, the pain undoubtedly corresponds to the type described by Lewis as peculiar to aortic incompetence.

Post-mortem statistics already cited indicate a high incidence of coronary ostial stenosis or occlusion in syphilitic angina (about 70 per cent), and an appreciable incidence of co-existent atheromatous coronary occlusion. Ostial stenosis is rarely found without aortic incompetence. In both conditions, cardiac ischæmia must be widespread throughout the heart, whereas in coronary atheroma it is commonly confined to the left ventricle, often to a small part of it. Such widespread ischæmia, once provoked, will not readily be relieved by a collateral circulation, as happens when it is limited to the territory of a single coronary branch. It appears that either stenosis of the coronary ostia or multiple atheromatous stenoses are capable of causing repeated and prolonged attacks of pain without any accompanying manifestations of acute cardiac infarction. 
Nocturnal Angina Pectoris

So little is known of the mechanism underlying nocturnal angina that its special connection with syphilis deserves attention. Serial cardiograms are seldom practicable at night, but we have recently obtained records from a case of postural and nocturnal angina, though not, as it happens, of syphilitic æatiology. This was a man, aged 53, who for six months had suffered almost nightly from severe anginal pain, though scarcely troubled in the daytime if he avoided exertion. Sometimes pain would start in bed before he fell asleep, and might recur several times before morning. Abstention from all food in the evening reduced the attacks, and a normal evening meal aggravated them. Gradual relief was obtained by sitting upright or getting out of bed, and more rapid relief from nitrites, which he consumed freely. Clinical and radiological findings were normal; blood pressure always normal; W.R. negative; there was inversion of T III only. Anginal pain could often be provoked at will by lying flat for ten minutes, and serial records obtained in attacks so induced showed unquestionable evidence of cardiac ischæmia (Fig. 2). In this case ischæmic pain was undoubtedly excited by the horizontal posture, as happened in many of our syphilitic cases.

A thrust-up diaphragm or too good a supper was Allbutt's explanation of nocturnal

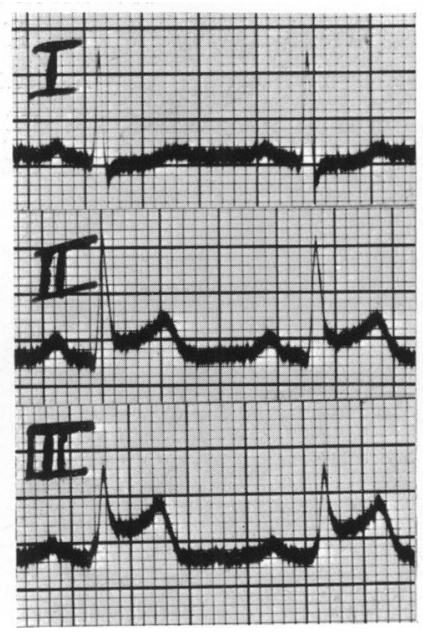

A

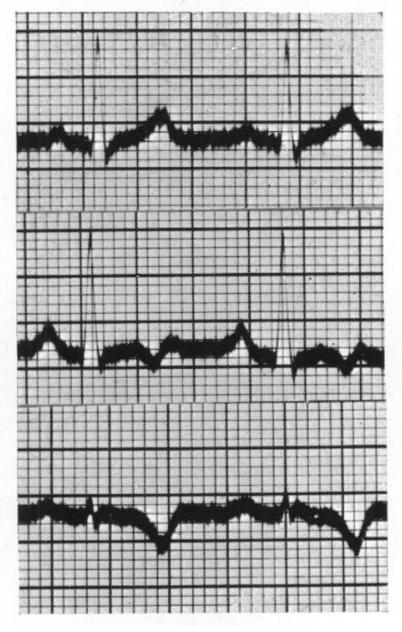

B

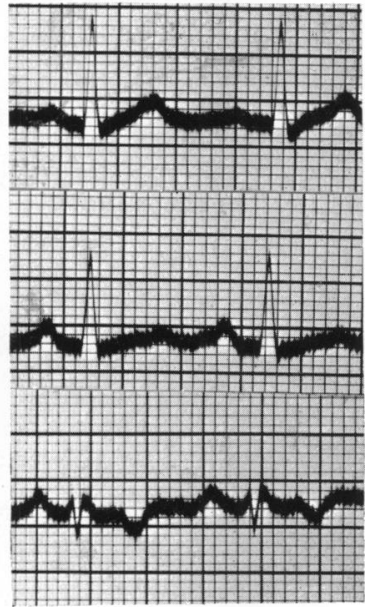

C

FIG. 2.-Serial electrocardiograms from a case of nocturnal angina in which attacks were provoked by lying flat. (A) During the pain; (B) Five minutes later; (C) Between attacks.

pain, and there is no doubt of the exciting influence of a full stomach. Wayne and Graybiel (1934) concluded that, in angina of effort, food acted by reflexly increasing the energy expenditure of the heart, and not by the mechanical effect of gastric distension. In a case of spontaneous angina, gastric inflation alone excited the attack. The recumbent posture, by elevating the diaphragm, may have a direct mechanical effect on the heart and aorta. In the so-called gastro-cardiac syndrome, pain of anginoid type is supposed to be due to bending of the aorta and tilting of the heart caused by a high diaphragm (Scherf, 1936). In the case of syphilitic aortitis, it is not difficult to believe that postural elevation of the diaphragm might cause or aggravate pressure pain from a grossly dilated aorta, as was suspected in several of our cases.

Assumption of the horizontal posture entails an increased cardiac output (McMichael, 1937) which, if maintained, would offer a simple mechanical explanation of nocturnal pain. But the relation of cardiac output to posture is complex and not yet finally settled. Hypercirculation at night was postulated by Eppinger and others (1924) in explaining cardiac asthma, and was attributed to peripheral vaso-dilatation.

A reflex nervous disturbance involving the heart is the alternative to a mechanical explanation of nocturnal pain in terms of posture. This might operate either by increasing cardiac energy 
expenditure or by reducing coronary flow. It is evident that the spontaneous anginal attacks of aortic incompetence are associated with raised blood pressure, but the primary cause is difficult to decide. The fact that nitrites, by means of coronary vaso-dilatation, so readily abolish the pain, naturally suggests excessive coronary vaso-constrictor tone as a cause. Anrep (1936) believes that the relation between blood pressure and coronary vaso-motor tone is important in anginal states, and that a rise of pressure may produce a coronary vaso-constrictor response sufficient to overcome the direct effect of a higher filling pressure on coronary flow.

Paradyspnaic Anginal Pain. The French conception of angina of decubitus as a satellite symptom of paroxysmal dyspnœa, due to left ventricular distension, is usually credited to Merklen (Tessier, 1905), who certainly described this association (Merklen, 1908). He did not ignore the possibility of ischæmia as the cause of the pain, but suggested that a diffuse sclerosis of the whole coronary tree might cause both ischæmia and dystrophic damage sufficient to weaken the heart, which thus became à la fois douloureux et faible.

Congestive failure and cardiac pain are usually quite separate events. Congestion, pulmonary or systemic, is related to mechanical inefficiency of one or other ventricle; pain is related to an inadequate blood-supply of some part of a ventricle that is as a whole mechanically efficient. In paroxysmal dyspnœa the right ventricle must remain efficient; but if its blood supply is restricted, for example by ostial stenosis or low diastolic pressure, any increased resistance in the lungs might evoke ischæmic pain before or coincident with the onset of pulmonary œdema. The influence of posture is explained by the increased amount of blood in the lungs in recumbency. Once pulmonary œdema has occurred, anoxæmia must further predispose to pain. It is not difficult to understand that, in conditions of incipient left heart failure, postural circulatory adjustments may precipitate sometimes dyspnœa, sometimes pain, and occasionally both together.

The onset of paroxysmal dyspnœa at night raises much the same problems as does the onset of nocturnal pain. There is the mechanical explanation in terms of posture, and the reflex nervous theory. Wassermann (1926) regarded cardiac asthma as a reaction of the central nervous system to stimuli from the aorta, and stressed the associated autonomic nervous disturbances. The view that aortitis causes paroxysmal dyspnœa dates back to Huchard, yet there is no more pathological evidence that uncomplicated aortitis causes dyspnœa than that it causes pain (Keefer and Resnik, 1926). A predominance of vagal over sympathetic tone during sleep has been postulated (Eppinger et al., 1924) and might favour coronary vaso-constriction, but this is purely hypothetical. If a reflex nervous origin of nocturnal angina is accepted as probable, at least in the case of aortic incompetence, the source of the exciting stimulus has yet to be determined.

Conclusion. The evidence reviewed suggests that generalized as opposed to focal cardiac ischæmia predisposes to spontaneous and nocturnal anginal pain, and that the horizontal posture is an important exciting cause. The modus operandi may be essentially mechanical or by way of reflex nervous reactions. In most cases of syphilitic aortitis, paroxysmal pain is ischæmic in nature and due to aortic incompetence often combined with stenosis of the coronary ostia. The response of pain to nitrites strongly supports this view. The possibility of pressure pain from a grossly dilated aorta being provoked by recumbency is admitted.

\section{Course AND Prognosis}

War conditions have interfered with the follow-up of our cases, but many of them have been under observation long enough to permit some prognostic conclusions. Of 103 cases, 37 have died, 21 are untraced, 45 were alive when we began to analyse these records before the war, and a few of them have been seen since. The average duration of life from the onset of anginal pain in the 37 dead was 2.4 years; 7 survived more than 5 years, and one for 11 
years. In the remaining 66 cases, 45 of which are alive and 21 untraced, the average duration of life from the onset of pain to the time they were last seen was 3.9 years. 27 of them have so far survived for more than 5 years and 5 for more than 10 years.

Though the expectation of life is appreciably less than in non-syphilitic angina, the outlook proved less gloomy than has been usually suggested. American statistics (Levy, 1936) give an average survival from the onset of symptoms in syphilitic aortitis of about 2 years or less, and German statistics are similar (Stadler, 1932).

With regard to the mode of death, 18 patients died in some form of anginal attack: 7 of them had a terminal status anginosus and 5 were reported as having " symptoms of coronary thrombosis"; 9 died in congestive failure, 6 died suddenly, and in the remaining 4, no details were available.

The effect of anti-syphilitic treatment was difficult to assess, but in general it did not remove the liability to anginal pain. If due allowance was made for the effect of rest and other routine measures, it was difficult to be sure that specific treatment appreciably influenced the anginal symptoms. In a few cases there was great improvement or even complete remission of symptoms for a time, and in a few others there was obvious aggravation of symptoms. On the assumption that it checks the progress of syphilitic inflammation in the aorta and thus prolongs life, we believe that anti-syphilitic treatment should always be given a trial, but aggravation of symptoms indicates its immediate cessation. Repetitive anginal attacks at rest or combined with paroxysmal dyspnœa are absolute contra-indications to anti-syphilitic treatment. The ordinary measures applicable to angina pectoris, such as rest in bed, sedatives, and nitrites, should not be neglected.

\section{SUMMARY AND CONCLUSIONS}

A series of 103 syphilitic patients subject to paroxysmal pain in the chest has been investigated with special regard to the clinical characteristics of the pain and its pathogenesis.

The age of onset of pain was evenly distributed over the fifth, sixth, and seventh decades, its maximal incidence being actually between 40 and 50 years. There were 80 men and 23 women, giving a sex ratio of 3.5 to 1 . A history of syphilitic infection was obtained in 31 cases; the average period between infection and the onset of pain was 24 years. A positive Wassermann reaction was recorded at some stage in 96 cases.

The main clinical findings were aortic incompetence in 67 cases; dilatation of the aorta in 59; cardiac enlargement, often slight, in 83; and essential hypertension in 26. Abnormal cardiograms were recorded in 57 of 94 cases examined.

76 patients were subject to angina of effort and 64 had pain apart from effort. Nocturnal attacks were common and were usually independent of paroxysmal dyspnœa. They tended to be prolonged but were relieved by nitrites. Paradyspnœic anginal attacks occurred in 13, a syphilitic status anginosus in 9, and symptoms of coronary thrombosis, not attributed to syphilis, in 10 cases.

Post-mortem findings in 12 cases are given and other pathological data are considered. The essential lesions of syphilitic angina are aortitis and aortic incompetence, usually combined with stenosis or occlusion of the coronary ostia. Atheromatous and thrombotic coronary occlusion may be coincident with syphilitic aortitis. Pathological evidence that uncomplicated aortitis causes anginal pain is lacking.

The thesis of an atypical or pseudo-anginal syndrome due to aortitis is examined and rejected. Paroxysmal pain in syphilitic cases conforms to recognized clinical varieties of angina pectoris such as are encountered in non-syphilitic coronary and aortic disease. Aortic incompetence and obstruction of the coronary ostia, which affect the blood-supply to the whole heart, and cause widespread rather than focal cardiac ischæmia, predispose to spontaneous and prolonged pain. The horizontal posture appears to be an important exciting 
cause of these nocturnal attacks. In paradyspnœic pain the effect of posture may be largely mechanical, but in other cases a reflex nervous mechanism may be operative. Consideration of certain cases also suggests that a relationship may exist between pressure pain from a dilated aorta and recumbency.

The clinical course, prognosis, and treatment are briefly described.

We wish to thank Professor James McIntosh for permission to include necropsy records from the BlandSutton Institute of Pathology.

\section{REFERENCES}

Allbutt, C. (1915). Diseases of the Arteries including Angina Pectoris, vol. ii, London.

Anrep, G. V. (1936). Studies in Cardiovascular Regulation. Lane Medical Lectures, California.

Barié, E. (1912). Traité pratique des Maladies du Cou et de l'Aorte, 3rd ed., Paris.

Bedford, D. E. (1936). British Encyclop. Med. Pract., vol. 1, London.

(1939). Lancet, 1, 1303.

Black, S. (1819). Clinical and Pathological Reports, Newry.

Blackall, J. (1814). Observations on the Nature and Cure of Dropsies, to which is added an Appendix contain** ing several cases of Angina Pectoris, with Dissections, etc., 2nd ed., London.

Blumgart, H. L., Schlesinger, M. J., and Davis, D. (1940). Amer. Heart J., 19, 1.

Campbell, M. (1936). Brit. Encyclop. Med. Pract., vol. 1, London.

Coombs, C. F. (1930). Lancet, 2, 227, 281, and 333. (1932). Quart. J. Med., 25, 179.

Cormia, F. E. (1935). Canad. med. Ass. J., 33, 613.

Corrigan, D. J. (1838). Dublin J. med. Sci., 12, 243.

Eppinger, H., Papp, L., and Schwarz, H. (1924). Ueber das Asthma Cardiale, Berlin.

Gallavardin, L. (1925). Les Angines de Poitrine, Paris. (1933). J. Med. Lyon., 14, 539. (1938). Ibid., 19, 527.

Heberden, W. (1772). Med. Tr. Roy. Coll. Phys., London, ii, 59.

(1802). Commentaries on the History and Cure of Diseases, London.

Herrick, J. B. (1931). Amer. Heart J., 6, 589.

Keefer, C. S., and Resnik, W. H. (1926). Arch. intern. Med., 37, 265.

Lamb, A. R., and Turner, K. B. (1932). Nelson Loose-leaf Medicine, vol. 4, New York.

Laubry, C., Mougeot, A., and Walser, J. (1925). Les Syndromes d'Aortite postérieure, Paris.

Levy, R. L. (1936). Diseases of the Coronary Arteries and Cardiac Pain, New York.

Lewis, T. (1929-31). Heart, 15, 305.

Longcope, W. T. (1913). Arch. intern. Med., 11, 15.

Love, W. S., and Warner, C. G. (1934). Amer. J. Syph. and Neurol., 18, 154.

Mackenzie, J. (1923). Angina Pectoris, London.

McMichael, J. (1937). Quart. J. exp. Physical, 27, 55.

Merklen, P. (1908). Leçons sur les Troubles fonctionnels du Cæur, Paris.

Morgagni, J. B. (1761). De Sedibus et Causis Morborum, Venice.

Oille, J. A. (1937). Canad. med. Ass. J., 37, 209.

Osler, W. (1897). Lectures on Angina Pectoris and Allied States, Edinburgh and London.

- (1906). Med. Chron., Manch., 2, 69.

Parkinson, J., and Bedford, D. E. (1928). Lancet, 1, 4.

Parry, C. H. (1799). An Inquiry into the Symptoms and Causes of the Syncope Anginosa, Bath.

Pincoffs, M. C., and Love, W. S. (1934). Amer. J. Syph. and Neurol., 18, 145.

Pratt, J. H. (1926). J. Amer. med. Ass., 87, 809.

Reid, W. D. (1930). Amer. Heart J., 6, 91.

Scherf, D. (1936). Klinik und Therapie der Herzkrankheiten und der Gefasserkrankungen, 3rd ed., Vienna.

Stadler, E. (1932). Syphilis des Herzens und der Gefässe, Dresden.

Tessier, J. P. (1905). Rôle de la Distension Cardiaque dans la Production de l'Angine de Poitrine, Paris.

van Muijden, N. H., and Scherf, D. (1934). Wien. klin. Wschr., 47, 746.

Wassermann, S. (1926). Neue klinische Gesichtspunkte zur Lehre von Asthma Cardiale, Berlin and Vienna.

Welch, F. H. (1876). Medico-Chirurg. Trans., London, 19, 59.

White, P. D., and Mudd, S. G. (1927). Amer. Heart J., 3, 1.

- and Bland, E. F. (1931-32). Ibid., 7, 1.

Willius, F. A. (1936). Proc. Mayo Clin., ii, 692.

Wilson, R. (1937). Amer. J. med. Sci., 194, 178.

Zimmermann-Meinzigen, O. (1936). Wien. Arch. inn. Med., 29, 161. 